\title{
Antioxidant Protective Effect of Newbouldia laevis on Hepatotoxicity in Alloxan-Induced Diabetes in Rats
}

\author{
Jane Ngozi Okafor ${ }^{1, ~ *, ~ O c h u k o ~ L u c k y ~ E r u k a i n u r e ~}{ }^{1}$, John Adebayo Ajiboye ${ }^{2}$, \\ Michael Obi Etoamaihe ${ }^{3}$, Ijeoma Lynda Eboagwu ${ }^{1}$, Sunday Oluwaseun Adenekan ${ }^{4}$ \\ ${ }^{1}$ Nutrition and Toxicology Division, Federal Institute of Industrial Research, Oshodi Lagos, Nigeria \\ ${ }^{2}$ College of Natural and Applied Sciences, Bells University of Technology, Ota, Nigeria \\ ${ }^{3}$ Analytical Division, Federal Institute of Industrial Research, Lagos, Nigeria \\ ${ }^{4}$ Department of Biochemistry, University of Lagos, Lagos, Nigeria
}

Email address:

zikaokee@yahoo.com (J. N. Okafor)

${ }^{*}$ Corresponding author

\section{To cite this article:}

Jane Ngozi Okafor, Ochuko Lucky Erukainure, John Adebayo Ajiboye, Michael Obi Etoamaihe, Ijeoma Lynda Eboagwu, Sunday Oluwaseun Adenekan. Antioxidant Protective Effect of Newbouldia laevis on Hepatotoxicity in Alloxan-Induced Diabetes in Rats. Journal of Diseases and Medicinal Plants. Vol. 6, No. 4, 2020, pp. 87-91. doi: 10.11648/j.jdmp.20200604.14

Received: November 25, 2020; Accepted: December 11, 2020; Published: December 22, 2020

\begin{abstract}
Due to some undesirable secondary reaction of synthetic drugs, natural products and plants with medicinal properties are been exploited in controlling and treating many chronic diseases including diabetes. Oxidative stress has a major effects in diabetes and the difficulties associated with it including hepatotoxicity. Newbouldia laevis is a traditional medicinal plant known to possess antimicrobial, anticonvulsant, sedative, analgesic, anti-inflammatory and antidiarrheal properties. However, there is scanty information on its utilization in diabetes management. This investigation was carried out to determine the potentials of aqueous ethanolic extract of Newbouldia laevis leaves to protect hepatic tissues of rats from diabetes caused by oxidative stress and hapatocellular injury. Diabetic condition was effected in rats by single intraperitoneal injection of alloxan. Rats were slaughtered by cervical dislocation after administration of Newbouldia leave extracts at dose of 200 and 400 $\mathrm{mg} / \mathrm{kg}$ bw for 21 days. Hepatic tissues were analysed for catalase, superoxide dismutase (SOD) and glutathione (GSH) activities, lipid peroxidation, lipid profile and protein content were also evaluated. Alkaline phosphatase (ALP), aspartate aminotransferase (AST) and alanine aminotransferase (ALT) which are hepatic biomarkers were analysed in the blood serum. Significant reduction $(\mathrm{p}<0.05)$ of GSH, catalase, and SOD activities were effected by diabetes induction, also rise in hepatic biomarkers and lipid peroxidation was observed. Treatment with extract at $200 \mathrm{mg} / \mathrm{kg}$ caused significant $(\mathrm{p}<0.05)$ increased activities of the studied antioxidant biomarkers and reduced lipid peroxidation. It also led to a reduced activity of hepatic biomarkers. These results shows antioxidant protective properties of $N$. laevis leaves against rise in oxidative stress and hepatocellular injury in diabetic rat's hepatic tissues at lower dose, indicating that the extract may possess antioxidant activities in diabetics.
\end{abstract}

Keywords: Antioxidant, Diabetes, Hepatic Biomarkers, Hepatocellular Injury

\section{Introduction}

Diabetes has been reported as a chronic ailment that exert influence on carbohydrate, protein and fat metabolism. This has been ascribed to insufficient insulin secretion for type 1 diabetes (T1D) and insulin insensitivity for type 2 diabetes (T2D). It is characterized by hyperglycemia which results to a number of problems that include retinopathy, nephropathy, steatosis, neuropathy, and damage to cerebral artery's microvascular [1]. This diabetic problems are greatly caused by rise in production of reactive oxygen species (ROS) [2]. Oxidative stress is the outcome of the variations in the body that favors' the production of free radicals over the body's antioxidant activities [2]. Hyperglycemia likewise diminishes or damages the internal antioxidant protection/security arrangement in some manner during diabetes [3]. These 
antioxidant defence procedure require both enzymatic and nonenzymatic action plan and defend/guard the body against free radicals. When disparity is created between endogenous antioxidants and free radical produced in the body, oxidative stress set in as a result of increased free radicals in the system [4]. Newbouldia laevis is amongst the many medicinal plants employed in traditional medicine for treating and taking care of various sicknesses such as stomach ache, breast cancer, constipation, malaria and diabetes mellitus. It is a medium sized angiosperm and member of the Bignoniaceae family, it is frequently referred to as African border tree and also known as fertility tree [9]. The antimicrobial activities of various fragments of the plant have been investigated in a number of research [10-12]. Its sedative effect in mice and rats has also been documented [13]. Its usefulness in the management of convulsion in children has been shown [14]. The ability of aqueous extract of the Stem Bark of Newbouldia laevis to prevent malaria in Mice infected with Plasmodium bergheih has been shown, its acute toxicity and potentials to prevent plasmodium documented $[15,16]$. Similarly, the ameliorative effect of Newbouldia laevis in Cadmiuminduced overian dysfunction [17], and the antihyperglycaemic activity of Newbouldia laevis leaf water extracts have been investigated [8]. The antisickling and anticancer effects has also been documented [18, 19]. This study aims at evaluating the ability of aqueous ethanolic extract of $N$. laevis leaves to protect hepatic tissues and hepatic biomarkers in diabetic rats from diabetes induced oxidative stress.

\section{Materials and Methods}

\subsection{Plant Material Collection and Drying}

Fresh leaves of Newbouldia laevis were plucked from a farm in University of Nigeria, Nsukka. The plant was botanically authenticated by Botanist at Plant Science and Biotechnology Department and a Voucher specimen (UNNHNO340B) was deposited in the herbarium of the University of Nigeria, Nsukka, Enugu State, Nigeria. The leaves were spread and allowed to air dry to a constant weight and pulverized with an electric grinder (Kenwood, Model BL335, Taiwan, China), packed and sealed in plastic bags for further use.

\subsection{Extraction of Plant Samples}

The pulverized Newbouldia laevis leaf (50 g) was extracted by cold maceration with $1000 \mathrm{~mL}$ aqueous ethanol (50:50) maintained on a mechanical shaker (Lab-line Orbit, Envron-Shaker, Lab line instrument, Melrose Park IL USA) for $48 \mathrm{~h}$. The resulting extract was filtered through Whatman's No 1 filter paper and centrifuged at a speed of $6000 \times \mathrm{g}$ for $30 \mathrm{~min}$ at $4^{\circ} \mathrm{C}$ (Beckman Coulter Avanti J-E centrifuge, USA) and further concentrated by evaporation under pressure in a rotary evaporator (Buchi, Brinkman $\mathrm{N}$ Instrument, Westbury, N. Y, USA) at $40^{\circ} \mathrm{C}$ to remove residual ethanol. The concentrated extract was frozen at $-80^{\circ} \mathrm{C}$ and freeze dried using a freeze dryer (Labconco- Virtis Company, Gardiner N. Y, USA) to obtain a powdered extract.

\subsection{Animals use in Experiment}

Forty two male albino rats of Wister strain weighing about $150-200 \mathrm{~g}$ were used for the study. They were fed on standard rat pellet diet and allowed to adapt for one week. They were provided water ad libitum and maintained under standard laboratory conditions of natural photo period of 12hr light - dark cycle. The study was carried out in accordance with the National Institute of Health Guidelines for the Care and Use of Laboratory Animals and was approved by the Animal Ethical Committee, Bells University of Technology, Ota, Ogun State, Nigeria.

\subsubsection{Induction of Diabetes}

Diabetes was induced by a single intraperitoneal injection of $180 \mathrm{mg} / \mathrm{kg}$ of alloxan monohydrate in normal saline water in a volume of about $3 \mathrm{~mL}$. After 72 hours of alloxan injection, rats with serum glucose level above $300 \mathrm{mg} / \mathrm{dl}$ were considered as diabetic [20] and were separated and used for the study.

\subsubsection{Experimental Design}

The rats were divided into seven groups, each consisting of six animals.

Group 1 - Normal rats + Pelletized rat chows

Group 2 - Diabetic (Untreated)

Group 3 - Diabetic + commercial drug ( $15.5 \mathrm{mg} / \mathrm{kg} \mathrm{bw})$ bw)

Group $4-$ Diabetic $+N$. laevis aqueous extract $(200 \mathrm{mg} / \mathrm{kg}$

Group $5-$ Diabetic $+N$. laevis aqueous extract $(400 \mathrm{mg} / \mathrm{kg}$ bw)

Group $6-$ Normal rats $+N$. laevis aqueous extract $(200$ $\mathrm{mg} / \mathrm{kg} \mathrm{bw}$ )

Group $7-$ Normal rats $+N$. laevis aqueous extract $(400$ $\mathrm{mg} / \mathrm{kg} \mathrm{bw}$ )

The rats were monitored daily for food and water intake, and body weight. Blood glucose levels of the rats were monitored on weekly basis with a glucometer. Treatment lasted for 21 days. At the end of experiment, the rats were fasted overnight and sacrificed by cervical dislocation.

\subsection{Preparation of Tissue Homogenates}

The organs (liver) were removed, rinsed in ice-cold 1.15\% $\mathrm{KCl}$ solution to wash off excess blood, blotted dry with filter paper and weighed. They were homogenized in four parts of homogenizing buffer and centrifuged at $10,000 \mathrm{rpm}$ for 15 min in an ultracentrifuge at a temperature of $-2^{\circ} \mathrm{C}$ to get the mitochondrial fraction. The supernatant (post-mitochondrial fraction) was decanted and stored at $-4^{\circ} \mathrm{C}$ for subsequent analysis. Each time the supernatant was outside the freezer, it was kept in ice bags.

The protein content of the tissue fractions of the organs were determined by Lowry's method using bovine serum albumin (BSA) as standard [21]. 


\subsection{Determination of Oxidative Stress Parameters}

Lipid peroxidation was determined by measuring malondialdehyde (MDA) formed by thiobarbituric acid reaction (TBAR) [22]. Catalase (CAT) activity was estimated by measuring the rate of decomposition of $\mathrm{H}_{2} \mathrm{O}_{2}$ [23]. The level of superoxide dismutase (SOD) activity was determined by the method of Misra and Fridovich [24], while the method of Ellman [25] was adopted in estimating the activity of reduced glutathione $(\mathrm{GSH})$.

\subsection{Serum Preparation}

Blood was collected with a $5 \mathrm{ml}$ syringe and needle by cardiac puncture and was centrifuged at $3000 \mathrm{x} \mathrm{g}$ for $10 \mathrm{~min}$ and the serum was analysed to evaluate some biochemical parameters.

\subsection{Biochemical Parameter Assays}

Enzymatic colorimetric method was used in determining hepatic and renal enzyme activities using a Randox kit which covers alkaline phosphatase (ALP), Aspartate aminotransferase (AST) and Alanine aminotransferase (ALT) according to the method of Amanvermez [26].

\subsection{Statistical Analysis}

To address the biological variability, each set of experiments was repeated at least three times. Differences between the groups were analysed by one-way analysis of variance (ANOVA) with the aid of SPSS software (SPSS Inc., Chicago, IL, USA) standard version 17. The p values of $<0.05$ were considered statistically significant for differences in mean using the least of significance difference, and data were reported as mean \pm standard deviation.

\section{Results}

\subsection{Antioxidant Activities of Experimental Groups}

Table 1. Shows a decline in GSH level with diabetes induction. This was observed to be restored on treatment with the standard commercial drug and single dose $(200 \mathrm{mg} / \mathrm{kg}$ bw) of $N$. laevis respectively. A much reduced level was also observed on treatment with double dose $(400 \mathrm{mg} / \mathrm{kg}$ bw) of $N$. laevis. On normal rats, single dose of $N$. laevis brought about a reduced level, while an increased activity was noticed in the double dose administered group.

Table 1. Antioxidant activities of experimental groups.

\begin{tabular}{llll}
\hline Groups & GSH & SOD & Catalase \\
\hline Group 1 & $0.4 \pm 0.05$ & $1.89 \pm 0.03$ & $15.58 \pm 0.50$ \\
Group 2 & $0.37 \pm 0.01$ & $1.78 \pm 0.10$ & $12.37 \pm 2.00$ \\
Group 3 & $0.43 \pm 0.03$ & $2.10 \pm 0.20^{*}$ & $14.70 \pm 5.20$ \\
Group 4 & $0.49 \pm 0.02$ & $2.42 \pm 0.30^{*}$ & $14.20 \pm 3.00$ \\
Group 5 & $0.27 \pm 0.02^{*}$ & $1.45 \pm 0.10^{*}$ & $11.09 \pm 2.80^{*}$ \\
Group 6 & $0.35 \pm 0.05^{*}$ & $1.79 \pm 0.20$ & $15.03 \pm 2.50$ \\
Group 7 & $0.56 \pm 0.01$ & $2.27 \pm 0.10$ & $14.52 \pm 2.30$ \\
\hline
\end{tabular}

Values $=$ mean \pm SD U/mg pro; $n=6$. $*$ Statistically significant $(\mathrm{p}<0.05)$ as compared to group 2.
Table 1 also indicated that diabetic rats that were not treated had decreased SOD and catalase activities. These were significantly $(\mathrm{p}<0.05)$ restored on treating the rats with the standard commercial drug and single dose of $N$. laevis respectively. Treating the rats with double dose of $N$. laevis resulted in reduced activities. Administration of $200 \mathrm{mg} / \mathrm{kg}$ bw (single dose) of $N$. laevis caused a reduced SOD but high catalase activities in the rats that were not diabetic.

\subsection{Lipid Peroxidation}

Figure 1 shows there was significant $(\mathrm{p}<0.05)$ rise in lipid peroxidation with induction of diabetes. Group treated with standard commercial drug showed increased level. However, administration of single and double doses of $N$. laevis caused a significant $(\mathrm{p}<0.05)$ decrease respectively. Reduced levels were also observed on administration of both doses to normal rats.

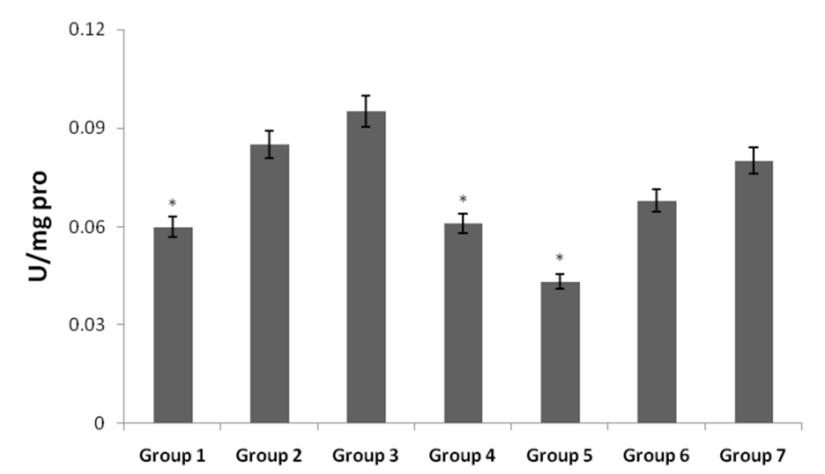

Figure 1. MDA levels of experimental groups. Values=mean $\pm S D ; n=6$. *Statistically significant $(p<0.05)$ as compared to group 2.

\subsection{Serum Biochemical Analysis}

Induction of diabetes caused an elevation in the amount of ALT, AST and ALP in the serum as depicted in figure 2. These were shown to decrease on treating the rats with standard commercial drug and single dose of $N$. laevis respectively. Treating the rats with $400 \mathrm{mg} / \mathrm{kg}$ (double dose) of $N$. laevis had no significant outcome on the elevated levels. When administered to normal rats, double dose of $N$. laevis was observed to cause an increased amount of the hepatic biomarkers.

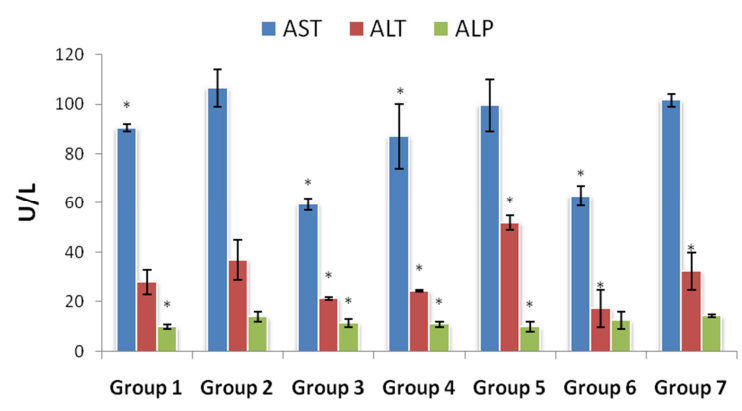

Figure 2. Effect of aqueous extract of $N$. laevis on hepatic biomarkers in blood serum of experimental rats. Values $=$ mean $\pm S D ; n=6$. *Statistically significant $(p<0.05)$ as compared to group 2. 


\section{Discussion}

Several studies have emphasized the part oxidative stress play in the manner of development of diabetes mellitus and the complications associated with it. [27]. This complications are ascribed to unrestrained elevated amount of free radicals with glucose oxidation that were reported to be the main culprit that gave rise to a concurrent decrease of the antioxidant protection system. The liver is seriously influenced or touched during diabetes, because of its pivotal and critical part in glucose and lipid homeostasis [6]. In this research, the changes caused as a result of administration of $N$. laevis aqueous ethanolic extract on diabetic - induced hepatotoxicity was investigated. The reduced GSH activity and increased lipid peroxidation in the hepatic tissues of diabetic rats that were not treated was an indication that they were stressed due to oxidation. GSH has been reported to be the major endogenous antioxidant and directly involved in the neutralization of ROS $[28,29]$. It also participates in maintaining exogenous antioxidants in their reduced (active) forms [28]. Lipid peroxidation (LPO) often open on to production of oxidant from numerous molecules, thereby increase destruction caused by oxidation and has been implicated in diabetes mellitus [30]. GSH and LPO are markers of oxidative stress [31]. Therefore, the observed increased activity of the GSH and lower amounts of LPO in $N$. laevis single dose treated diabetic rats indicates that the extract had antioxidant protective potentials. The increase in the activities of SOD and catalase (additional researched) antioxidant biomarkers that was noticed in single dose treated diabetic rats further portrays its antioxidant potency. The activities of SOD and catalase has been shown to decrease as a result of oxidative stress [32]. These enzymes are mostly effective in maintaining the physiological amount of hydrogen peroxide and oxygen through getting rid of organic peroxides and hydro peroxides and acceleration of dismutation of oxygen radicals produced from oxidation of glucose [33]. The reduced activities of these biomarkers in the double dose $N$. laevis treated diabetic rats portray an enhanced oxidative stress. Thus, implying that $N$. laevis may possess pro-oxidant activities in diabetics at higher concentrations. The reduced activities of the biomarkers on administration of single dose of $N$. laevis to normal rats indicates its effects on hepatic tissues.

When hepatocellular injury occurs, there is raise or increase in the activities of ALT, AST and ALP [34]. In our investigation, induction of diabetes led to an increased activity of the studied hepatic biomarkers in blood serum, suggesting an incidence of hepatic injury. When cellular damage occurs, there is let out of these enzymes from the cytoplasm into the blood transmission which is probably the reason for the increased activity of the enzymes and this is peculiar to oxidative stress as indicated in numerous investigations. $[4,6]$. The reduced activities in rats administered single dose of $N$. laevis indicate the protective effect of the extract against diabetic - induced hepatic injury. Research has indicated that ethanolic extract from $N$. laevis stem and leaves had similar result when used in treatment of diabetes [6].

The increased activity in the double dose further implicates treatment with the extract at higher concentration as a prooxidant and therefore may not be recommended. These corroborate with the above observed antioxidant effect of both doses respectively. The increased activities of these enzymes after administration of double dose of the extract to normal rats reveals the hepatocellular effects of $N$. laevis in healthy animals at higher concentration.

\section{Conclusion}

The result obtained from this study indicate that aqueous ethanolic extract of $N$. laevis leaves possess hepatoprotective properties that could suppress oxidative stress related complication in diabetes. This is evidenced by its antioxidant protective ability against rise in oxidative stress and hapatocellular injury in hepatic tissues of rats induced with diabetes. However, there is need for further investigation on the bioactive components responsible and mechanisms of action for a more conclusive result.

\section{Conflict of Interest}

All the authors do not have any possible conflicts of interest.

\section{References}

[1] Auslander W, Haire-Joshu D, Houston C, Rhee CW, Williams $\mathrm{JH}$. A controlled evaluation of staging diatary patterns to reduce the risk of diabetes in African-American women. Diabetes Care 2002; 25: 809-814.

[2] Wrighten SA, Piroli GG, Grillo CA, Reagan LP. A look inside the diabetic brain: Contributors to diabetes-induced brain aging. Bioc Biophy Acta 2009; 1792: 444-453.

[3] Saxena AK, Srivastava P, Kale RK, Baquer NZ. Impaired antioxidant status in diabetic rat liver: Effect of vanadate. Biochem Pharmacol. 1993; 45: 539-542.

[4] Abovwe JA, Erukainure OL, Oke OV, Okafor OY, Ajiboye AJ. Modulatory effects of Globimetula braunii on lipid peroxidation and antioxidant status in hypercholesteremic rats. Inventi Rapid: Ethnopharm. 2010; 1 (1); ep25.

[5] Iwu MM. Traditional Igbo medicine. Institute of African Studies, University of Nigeria, Nsukka. 1983; Pp. 122-144.

[6] Anaduaka EG, Ogugua VN, Agu CV, Okonkwo CC. Ethanol extract of Newbouldia laevis stem and leaves modulate serum liver marker enzymes and antioxidant enzymes activities in diabetic rats. Afri J Biotech. 2014; 13 (22): 2265-2272.

[7] Ajah O, Unegbu CC, Uzomba NI, Nnaoma IE, Chinyere IG. Hypoglycemic activity of aqueous leave extract of Newbouldia laevis on alloxan induced diabetes in male albino rats. European Journal of Basic and Applied Sciences 2016; 3 (2): $15-18$. 
[8] Vincent UI, Ejike DE, Moses DA, Denen A, Mazi I. Newbouldia laevis leaf facilitates insulin secretion, glucose uptake and pancreatic function in Alloxan-induced hyperglycaemia in Wistar rats. International Journal of Pharmaceutical Sciences and Research 2018; 9 (12): 50795085 .

[9] Timothy KO, Adewumi AM, Emmanuel AO, Olayemi AM. Ethanolic extract of leaves of Newbouldia laevis attenuates glycosylation of hemoglobin and lipid peroxidation in diabetic rats. Amer J Pharmacol Toxicol. 2013; 8 (4): 179186.

[10] Kuete V, Eyong KO, Folefoc GN, Beng VP, Hussain H, Krohn $\mathrm{K}$, A E Nkengfack AE. Antimicrobial activity of the methanolic extract and of the chemical constituents isolated from Newbouldia laevis. Pharmazie. 2007; 62: 552-556.

[11] Ogunlana OE, Ogunlana OO. In vitro assessment of antioxidant activity of Newbouldia laevis. J Med Plants Res. 2008; 2: 176-179.

[12] Obum-Nnadi CN, Okey-Ndeche FN, Nnagbo PA, Ohabughiro NB. Phytochemical and Antibacterial Activities of Newbouldia laevis leaves (Ogirishi) on two Drug Resistant Bacteria. International Journal of Research and Review 2020; 7 (5): 59-66.

[13] Amos S, Binda L, Vongtau H, Chindo B, Abbah J, Sambo N, Odin EM, Okwute SR, Arah P, Wambebe C, Gamaniel K. Sedative effects of the methanolic leaf extract of Newbouldia laevis in mice and rats. Boll Chim Farm. 2002; 141 (6): 471 475.

[14] Akunyili DN. Anticonvulsant activity of the ethanol extract of Newbouldia laevis. 2nd NAAP Scientific Conference. 2000; $155-158$.

[15] Salawu MO, Raji NH, Oloyede H, Oyelola B. Antimalarial Activity of Aqueous Stem Bark Extract of Newbouldia laevis in Plasmodium berghei-Infected Mice. Centrepoint Journal (Science Edition) 2020; 26 (1): 14-36.

[16] Ndarubu TA, Jigam AA, Olufunmilola AH, Famous OI, Damola AS. Acute Toxicity Studies and Anti-plasmodial Potentials of Newbouldia laevis and Crateva adansonii in Plasmodium Berghei-infected Mice. Iranian Journal of Toxicology. 2020; 14 (2): 93-104.

[17] Oyewopo AO, Olaniyi KS, Oniyide AA, Sanya OA, Amusa OA, Faniyan OF, Eweoya OO. Aqueous Extract of Newbouldia laevis Abrogates Cadmium-Induced Ovarian Dysfunction in Adult Wistar Rats. Journal of Pharmacy and Pharmacology 2019; 7: 110-118.

[18] Dermane A, Kpegba K, Metowogo K, Joppa MK, EkluGadegbeku K, A. Kodjo Aklikokou AK, Gbeassor M. Evaluation of the anti-sickling activity of Newbouldia laevis P. Beauv extracts. Int. J. Biol. Chem. Sci. 2018; 12 (6): 28082817.

[19] Kuete V, Wabo HK, Eyong KO, Feussi, MT, Wiench B, Krusche B, Tane P, Folefoc GN, Efferth T. Anticancer activities of six selected natural compounds of some cameroonian medicinal plants. PLoS ONE. 2011; 6 (8): e21762.
[20] Khathi A, Serumula MR, Myburg RB, Heerden FRV, Musabayane TC. Effects of Syzygium aromaticum-Derived Triterpenes on Postprandial Blood Glucose in StreptozotocinInduced Diabetic Rats following Carbohydrate Challenge. Plos One 2013; 8 (11): e81632.

[21] Lowry OH, Rosebrough NJ, Farr AL, Randall RJ. Protein measurement with folin-phenol reagent. J Biol Chem. 1951; 193 (1): 265-275.

[22] Chowdhury P, Soulsby M. Lipid peroxidation in rat brain is increased by simulated weightlessness and decreased by a soy-protein diet. Ann Clin Lab Sci. 2002; 32 (2): 188-192.

[23] Aebi HE. Methods in Enzymatic Analysis. Academic press, New York. 1983.

[24] Misra H, Fridovich I. The role of superoxide anion in the auto oxidation of epinephrine and a simple assay for Superoxide Dismutase. J Biol Chem. 1972; 247 (10): 3170-3175.

[25] Ellman GL. Tissue sulphydryl groups. Arch Biochem Biophy. 1959; 82: 70-77.

[26] Amanvermez R, Ankaralı S, Tunçel OK, Tomak L, Alvur M. Effect of chronic high dose-alcohol consumption on the general biochemical parameters. Turk J Biochem. 2009; 34 (3): 113-120.

[27] Ugochukwu NH, Cobourne MK. Modification of renal oxidative stress and lipid peroxidation in streptozotocininduced diabetic rats treated with extracts from Gongronema latifolium leaves. Clin Chim Acta 2003; 336: 73-81.

[28] Scholz RW, Graham KS, Gumpricht E, Reddy CC. Mechanism of interaction of vitamin E and glutathione in the protection against membrane lipid peroxidation. Ann NY Acad Sci. 1989; 570 (1): 514-517.

[29] Erukainure OL, Ajiboye JA, Adejobi RO, Okafor OY, Adenekan SO. Protective effect of pineapple (Ananas cosmosus) peel extract on alcohol-induced oxidative stress in brain tissues of male albino rats. Asian Pac J Trop Dis. 2011; 1 (1): 5-9.

[30] Davì G, Chiarelli F, Santilli F, Pomilio M, Vigneri S, Falco A, Basili S, Ciabattoni G, Patrono C. Enhanced Lipid Peroxidation and Platelet Activation in the Early Phase of Type 1 Diabetes Mellitus: Role of Interleukin-6 and Disease Duration. Circulation 2003; 107: 3199-3203.

[31] Onyema OO, Farombi EO, Emerole GO, Ukoha AI, Onyeze GO. Effect of vitamin $\mathrm{E}$ on monosodium glutamate induced hepatoxicity and oxidative stress in rats. Indian $\mathrm{J}$ Biochem Biophys. 2005; 43: 20-24.

[32] Nandhini ATA, Thirunavukkarasu V, Ravichandran MK, Anuradha CV. Effect of taurine on biomarkers of oxidative stress in tissues of fructose-fed insulin-resistant rats. Singapore Med J. 2005; 46 (2): 82-87.

[33] Pari L, Latha M. Protective role of Scoparia dulcis plant extract on brain antioxidant status and lipid peroxidation in STZ diabetic male Wistar rats. BMC Complement Alt Med. 2004; $4: 16$

[34] Kaneko JJ, Harvey JW, Michael LB. Clinical Biochemistry of Domestic Animals. 5 th ed. N. 